\title{
Effects of opt-in letters in a National Health Service psychotherapy service
}

\author{
Simon Houghton, ${ }^{1}$ Dave Saxon, ${ }^{1,2}$ Amanda Smallwood'
}

The Psychiatrist (2010), 34, 507-510, doi: 10.1192/pb.bp.109.027581

${ }^{1}$ Psychotherapy Department, Sheffield Health and Social Care NHS Foundation Trust, Sheffield; ${ }^{2}$ School of Health and Related Research, University of Sheffield

Correspondence to Simon Houghton (simon.houghton@shsc.nhs.uk)

\begin{abstract}
Aims and method Up to a third of clients referred to National Health Service (NHS) mental health services will miss their first appointment. Opt-in systems are widely used to reduce non-attendance but there has been little published research examining the effects of such methods on clients. A cohort study with non-randomised historical controls was used to examine the introduction of an opt-in letter as the route to a first appointment in an NHS psychotherapy service.
\end{abstract}

Results The introduction of the opt-in letter slightly reduced non-attendance rates for first appointments, but this was at the expense of overall access to the service for the highest prevalence disorders.

Clinical implications It appears that although an opt-in system can reduce nonattendance at first appointments, it may have an unintended consequence of denying access to clients with the most common mental health problems such as anxiety disorders and depression.

Declaration of interest None.
Up to a third of people referred to National Health Service (NHS) mental health services miss their first appointment, ${ }^{1}$ with early non-attendance predicting withdrawal from psychological therapies later in treatment. ${ }^{2}$ One solution to this problem has been the introduction of an opt-in system. This typically involves clients being sent a letter asking them to contact the service to book a first appointment, rather than one being allocated to them by the service. Such a system then excludes clients who do not respond. Reports of the use of opt-in systems have shown a reduction in waiting time to the first appointment and a reduced non-attendance rate from around $27 \%$ to $4 \% .^{3}$ It has been suggested that there might be a systematic bias in opt-in systems in that they admit a particular group of clients to psychological therapy services while deterring and not admitting others. This possible bias might specifically disadvantage clients already known to be more difficult to engage with services. ${ }^{4}$ To date there has been no analysis of demographic or diagnostic data relating to the use of opt-in systems. This paper describes the effects of introducing an opt-in letter as the route to a first appointment in an NHS psychotherapy service. Specifically, we predicted that the introduction of an opt-in letter would reduce non-attendance at first appointments; we also aimed to evaluate whether this method discriminated against any particular group of clients.

\section{Method}

A cohort study with non-randomised historical controls was designed at the time of the introduction of the opt-in system to the Sheffield Health and Social Care NHS
Foundation Trust. People referred to the service were sent an opt-in letter within a week of their referral being received. This letter acknowledged their referral by a named professional to the psychotherapy service, and asked them to call the department secretaries on a specific telephone number to book an initial assessment appointment. Demographic and client problem data were collected relating to all referrals for the complete year prior to the introduction of the opt-in letters (year 1) and for the following year (year 2). Subsequently, five groups of clients were identified for description and analysis:

1 in year 1 , those who attended their first appointment prior to the opt-in system;

2 in year 1, those who did not attend their first appointment prior to the opt-in system;

3 in year 2, those who did not opt in;

4 in year 2, those who opted in and attended the first appointment;

5 in year 2, those who opted in but did not attend the first appointment.

Advice was sought regarding governance of the evaluation, and it was confirmed that ethical approval was not needed as this project fell within the definition of service evaluation: that is, the evaluation aimed to assess the impact of a local change in service delivery that was applied equally to all clients in the population served. Service use and client demographic information was collected from routine audit data, and client problems and diagnoses were identified from the original referral letter. 


\section{Statistical analysis}

After data collection the information was anonymised and exported to SPSS version 16.0 on Windows for statistical analysis. This analysis considered referral patterns and overall differences between the two years; each variable was analysed in terms of those who opted in and those who did not; those who opted in but subsequently did not attend; and differences between those who attended in year 1 and those who attended in year 2 .

\section{Results}

Table 1 describes the clients referred in year 1 (prior to the opt-in system) and year 2 (after introduction of the opt-in system).

\section{Differences in referrals between the two years}

There were 331 clients referred to the psychotherapy service in year 1 and 289 in year 2 . In year 2 compared with year 1 , a greater proportion of referrals were for men $(44 \% v$. $38 \%$; $\left.\chi_{(1)}^{2}=2.41, P=0.12\right)$ and a greater proportion were 'not White British or European' (8\% v. 5\%; $\left.\chi^{2}{ }_{(1)}=2.04, P=0.15\right)$, but neither difference was statistically significant. In year 2 , a greater proportion of referrals came from psychiatrists, Social Services and other sources than in year 1. As a result, the proportion of clients referred from general practitioners (GPs) fell significantly from $73 \%$ to $52 \% \quad\left(\chi_{(1)}^{2}=30.76\right.$, $P<0.001)$. The proportion of referrals in each problem category were similar across both years $\left(\chi_{(7)}^{2}=8.90\right.$, $P=0.26)$. Overall, in the first year $67(20 \%)$ people did not attend their first appointment and 264 (80\%) did attend, whereas in the second year $58(20 \%)$ of those referred did not opt in, $42(15 \%)$ opted in then did not attend and 189 (65\%) opted in and attended their first appointment. The proportion of people referred who did not attend an arranged appointment therefore fell from $20 \%$ to $15 \%$ $\left(\chi_{(1)}^{2}=3.41, P=0.065\right)$ following the introduction of the optin system, which was not statistically significant. However, the overall number of people referred who attended their first assessment fell significantly from $80 \%$ to $65 \%$ $\left(\chi_{(1)}^{2}=16.34, P<0.001\right)$.

\section{Year 2 clients who did or did not opt in}

There was no statistically significant difference between the proportion of men referred who opted in and the proportion of women (men $78 \%$, women $82 \%$; $\chi_{(1)}^{2}=0.65, P=0.42$ ), or the proportion of 'not White British/European' (86\%) compared with 'White British/European' clients (79\%; Fisher's exact test, $P=0.58$ ). All clients referred by Social Services, $83 \%$ of those referred by GPs and $83 \%$ referred by psychiatrists opted in, but only $63 \%$ of clients referred by other sources opted in. Grouping those referred by Social Services, GPs and psychiatrists, there was a highly significant difference in the proportion that opted in compared with other referral sources $\left(\chi_{(1)}^{2}=11.06\right.$, $P=0.001)$. Considering the primary problem identified by the referrer, $82 \%$ of clients with depression and $85 \%$ of those with obsessive-compulsive disorder opted in, whereas $94 \%$ of those with post-traumatic stress disorder, personality disorder, eating disorder, body dysmorphic disorder and 'other' disorders (grouped owing to small numbers) opted in. Only $70 \%$ of those with anxiety opted in, and the

\begin{tabular}{|c|c|c|c|c|c|}
\hline & \multicolumn{2}{|c|}{ Year $1(n=331)$} & \multicolumn{3}{|c|}{ Year $2(n=289)$} \\
\hline & $\begin{array}{c}\text { Attended } \\
n\end{array}$ & $\begin{array}{c}\text { Did not attend } \\
n\end{array}$ & $\begin{array}{l}\text { Opted in and } \\
\text { attended } \\
n\end{array}$ & $\begin{array}{c}\text { Opted in and } \\
\text { did not attend } \\
n\end{array}$ & $\begin{array}{c}\text { Did not opt in } \\
n\end{array}$ \\
\hline Total, $n$ & 264 & 67 & 189 & 42 & 58 \\
\hline \multicolumn{6}{|l|}{ Gender } \\
\hline Male & 89 & 35 & 75 & 23 & 28 \\
\hline Female & 175 & 32 & 114 & 19 & 30 \\
\hline \multicolumn{6}{|l|}{ Ethnicity } \\
\hline White British/European & 246 & 62 & 168 & 39 & 55 \\
\hline Other (not White British/European) & 11 & 5 & 16 & 3 & 3 \\
\hline Not recorded & 7 & 0 & 5 & 0 & 0 \\
\hline \multicolumn{6}{|l|}{ Referral source } \\
\hline General practitioner & 197 & 45 & 97 & 27 & 26 \\
\hline Psychiatrist & 26 & 10 & 56 & 9 & 13 \\
\hline Social Services & 3 & 0 & 7 & 0 & 0 \\
\hline Other (including $\mathrm{CMHT}$, dentist) & 34 & 12 & 26 & 6 & 19 \\
\hline Not recorded & 4 & 0 & 3 & 0 & 0 \\
\hline \multicolumn{6}{|l|}{ Client problem } \\
\hline Depression & 65 & 16 & 48 & 13 & 14 \\
\hline Anxiety & 104 & 26 & 65 & 11 & 32 \\
\hline OCD & 45 & 10 & 39 & 11 & 9 \\
\hline PTSD & 8 & 3 & 10 & 4 & 0 \\
\hline Personality disorder & 11 & 1 & 6 & 1 & 3 \\
\hline Eating disorder & 4 & 2 & 3 & 0 & 0 \\
\hline Body dysmorphic disorder & 11 & 3 & 3 & 0 & 0 \\
\hline Other & 16 & 6 & 15 & 2 & 0 \\
\hline
\end{tabular}

CMHT, community mental health team; OCD, obsessive-compulsive disorder; PTSD, post-traumatic stress disorder. 
Table 2 Clients referred for a first appointment, with relative risk of not attending for each client characteristic

\begin{tabular}{|c|c|c|c|c|}
\hline Client characteristic & $\begin{array}{l}\text { Year } 1 \\
n(\%)\end{array}$ & $\begin{array}{c}\text { Year } 2 \\
n(\%)\end{array}$ & $\begin{array}{c}\text { Statistical } \\
\text { significance }\end{array}$ & $\begin{array}{c}\text { Relative } \\
\text { risk }\end{array}$ \\
\hline \multicolumn{5}{|l|}{ Gender } \\
\hline Attended & $89(72)$ & $75(60)$ & \multirow{2}{*}{$\chi_{(1)}^{2}=4.2, P=0.041$} & \multirow[t]{2}{*}{1.4} \\
\hline Did not attend/opt in & $35(28)$ & $51(40)$ & & \\
\hline \multicolumn{5}{|l|}{ Female } \\
\hline Attended & $175(84)$ & $114(70)$ & \multirow[t]{2}{*}{$\chi_{(1)}^{2}=11.37, P=0.001$} & \multirow[t]{2}{*}{1.9} \\
\hline Did not attend/opt in & $32(16)$ & $49(30)$ & & \\
\hline \multicolumn{5}{|l|}{ Ethnicity } \\
\hline \multicolumn{5}{|l|}{ White British/European } \\
\hline Attended & $246(80)$ & $168(64)$ & \multirow{2}{*}{$\chi_{(1)}^{2}=17.66, P<0.001$} & \multirow[t]{2}{*}{1.8} \\
\hline Did not attend/opt in & $62(20)$ & $94(36)$ & & \\
\hline \multicolumn{5}{|c|}{ Other (not White British/European) } \\
\hline Attended & $11(69)$ & $16(73)$ & \multirow[t]{2}{*}{ Fisher's exact test $P=1.00$} & \multirow[t]{2}{*}{0.9} \\
\hline Did not attend/opt in & $5(31)$ & $6(27)$ & & \\
\hline \multicolumn{5}{|l|}{ Referral } \\
\hline \multicolumn{5}{|l|}{ Referred by GP } \\
\hline Attended & $197(81)$ & $97(65)$ & \multirow[t]{2}{*}{$\chi_{(1)}^{2}=13.84, P<0.001$} & \multirow[t]{2}{*}{1.9} \\
\hline Did not attend/opt in & $45(19)$ & $53(35)$ & & \\
\hline \multicolumn{5}{|l|}{ Referred by psychiatrist } \\
\hline Attended & $26(72)$ & $56(72)$ & \multirow[t]{2}{*}{$\chi_{(1)}^{2}=0.0, P=0.962$} & \multirow[t]{2}{*}{1.0} \\
\hline Did not attend/opt in & $10(28)$ & $22(28)$ & & \\
\hline \multicolumn{5}{|l|}{ Referred by Social Services } \\
\hline Attended & $3(100)$ & $7(100)$ & & \\
\hline Did not attend/opt in & $0(0)$ & $0(0)$ & & \\
\hline \multicolumn{5}{|c|}{ Referred by 'other' (e.g. CMHT, dentist) } \\
\hline Attended & $34(74)$ & $26(51)$ & \multirow[t]{2}{*}{$\chi_{(1)}^{2}=5.39, P=0.020$} & \multirow[t]{2}{*}{1.9} \\
\hline Did not attend/opt in & $12(26)$ & $25(49)$ & & \\
\hline \multicolumn{5}{|l|}{ Client problem } \\
\hline \multicolumn{5}{|l|}{ Depression } \\
\hline Attended & $65(80)$ & $48(64)$ & $\chi_{(1)}^{2}=5.2, P=0.023$ & 1.8 \\
\hline Did not attend/opt in & $16(20)$ & $27(36)$ & & \\
\hline Anxiety & & & & \\
\hline Attended & $104(80)$ & $65(60)$ & $\chi_{(1)}^{2}=11.25, P<0.001$ & 2.0 \\
\hline Did not attend/opt in & $26(20)$ & $43(40)$ & & \\
\hline OCD & & & & \\
\hline Attended & $45(82)$ & $39(66)$ & $\chi_{(1)}^{2}=3.6, P=0.057$ & 1.9 \\
\hline Did not attend/opt in & $10(18)$ & $20(34)$ & & \\
\hline Other problem & & & & \\
\hline Attended & $50(77)$ & $37(79)$ & $\chi_{(1)}^{2}=0.0, P=0.821$ & 0.9 \\
\hline Did not attend/opt in & $15(23)$ & $10(21)$ & & \\
\hline
\end{tabular}

$\mathrm{CMHT}$, community mental health team; GP, general practitioner; $\mathrm{OCD}$, obsessive-compulsive disorder.

difference between this and all other problem categories was statistically significant $\left(\chi_{(1)}^{2}=9.83, P=0.002\right)$.

\section{Year 2 clients who opted in but subsequently did not attend}

Considering only year 2 clients who opted in, no variable showed a statistically significant difference in terms of those who subsequently attended or did not attend. A larger proportion of males than females $\left(24 \% v .14 \%, \chi^{2}{ }_{(1)}=3.20\right.$, $P=0.074)$, 'White British/European' than 'not White British/European' (19\% v. 16\%, Fisher's exact test, $P=1.00$ ) and GP referrals than other sources $\left(\chi_{(1)}^{2}=2.03, P=0.154\right)$ opted in then did not attend. A fifth $(22 \%)$ of clients with obsessive-compulsive disorder, $21 \%$ with depression, $15 \%$ with anxiety and $16 \%$ with other problems did not attend their first appointment $\left(\chi_{(3)}^{2}=1.75, P=0.627\right)$.

\section{Differences between those attending in year 1 and those attending in year 2}

A significantly smaller proportion of both men and women attended their assessments following the introduction of the opt-in letter (Table 2). The relative risk (RR) of not accessing the service was 1.4 times greater for men in year 2 compared with year 1, and was nearly twice as great (1.9) for women. The proportion of 'not White British/European' clients who attended rose slightly but insignificantly following the introduction of the opt-in letter. There was a highly significant reduction in 'White British/European' clients attending an assessment in year 2. The latter were 1.8 times more likely not to access the service in year 2 . All those referred by Social Services attended in both years, and the attendance rate for psychiatrist referrals was virtually the same in both years. However, the attendance rate for GP referrals fell significantly, as did referrals from 'other' sources. Both were almost twice as likely not to be seen in year 2 compared with year $1(R R=1.9)$. There was a 
statistically significant reduction in the attendance rate for clients with obsessive-compulsive disorder and depression, and those with anxiety were twice as likely not to access the service in year 2 compared with year 1 . There was no statistically significant change in attendance rate for those with other problems. Within this category, clients with a personality disorder had a RR of 4.8, indicating that these people were almost five times more likely not to access the service in year 2 compared with year 1 ; however, the number of clients was small (Table 1).

\section{Discussion}

It appears from our findings that the introduction of an optin letter reduced overall non-attendance at first appointments in an NHS psychotherapy service from 20 to $14 \%$ but that this fall was not statistically significant. This reduction is less dramatic than previously reported by Hawker, ${ }^{3}$ but derived from a lower baseline than that study. The proportion of all referred individuals who attended their assessment for therapy also fell from 80 to $65 \%$, and this drop was statistically significant. A number of client factors were associated with not opting in or not attending following the introduction of the letter. People referred from sources other than GPs, psychiatrists and Social Services and those with anxiety problems appear less likely to have opted in during year 2 . However, once clients had opted in, none of the characteristics described appeared to be significant in whether the client subsequently attended or not.

Comparing client groups who attended an assessment before and after the introduction of the opt-in letter, most categories of client seemed to be adversely affected. Indeed, only those 'not White British/European', those referred by psychiatrists or Social Services and those with problems other than depression, anxiety, obsessive-compulsive disorder and personality disorder did not seem to be adversely affected, but the number of clients in some of these categories is small. Clients with an anxiety problem were also more likely not to opt in. We suspect that the specific type of anxiety problem might be relevant in this finding and there may be other pertinent problems contained within the 'other' category, but our data-set was too small to break this group down with meaningful results. The opt-in letter was associated with less attendance in year 2 by clients referred by GPs but there was no difference in attendance by psychiatrist referrals.

There are a number of limitations to consider when interpreting the presented data. First, there were observed changes in overall referral patterns between the two years being examined. Overall, there was a fall in referrals in year 2 from 331 to 289 , with a greater proportion of clients being male and non-White British/European. There were more referrals from psychiatrists and fewer from GPs in the second year, and some slight changes in the proportions of client problems observed. Methodological limitations in this study should also be acknowledged. The use of historical non-randomised controls may introduce a systematic bias and assumes that the two groups of patients are comparable when they may not be. Within this single, relatively small service there were no changes in staff or care pathways over the period of interest, although external factors influencing referrals to the service may have changed from year 1 to year 2 . The use of a single psychotherapy service may also be too specific a service area for results to be widely generalisable. A prospective experimental design whereby patients are randomly allocated to receive an opt-in letter or another method of introduction across a wider range of services would overcome these limitations. This evaluation of a service improvement initiative may have implications for the organisation of psychological therapies in the NHS.

Our data suggest that an opt-in system can reduce the numbers of those not attending first appointments, perhaps making more efficient use of a scarce resource. However, our data also suggest that the opt-in system had the unintended consequence of reducing the proportion of referred clients receiving an assessment from four-fifths to less than two-thirds. This suggests that the opt-in system may discriminate against people with mental health problems at a time when there is a need to improve access to psychological therapies.

\section{About the authors}

Simon Houghton is Consultant Cognitive Behavioural Psychotherapist, Psychotherapy Department, Sheffield Health and Social Care NHS Foundation Trust, Dave Saxon is Research Associate/Data Manager, School of Health and Related Research, University of Sheffield, and Psychotherapy Department, Sheffield Health and Social Care NHS Foundation Trust, and Amanda Smallwood is Team Secretary, Psychotherapy Department, Sheffield Health and Social Care NHS Foundation Trust, UK.

\section{References}

1 Hoare P, Norton B, Chisholm D, Parry-Jones W. An audit of 7000 successive child and adolescent psychiatry referrals in Scotland. Clin Child Psychol Psychiatry 1996; 1: 229-49.

2 Aubrey R, Self R, Halstead JE. Early non-attendance and subsequent attrition from psychological help. Clin Psychol 2003; 32: 6-10.

3 Hawker DSJ. Increasing initial attendance at mental health out-patient clinics: opt-in systems and other interventions. Psychiatr Bull 2007; 31: 179-82.

4 Care Services Improvement Partnership. Designing Primary Care Mental Health Services. Department of Health, 2006. 